(RESEARCH ARTICLE)

\title{
Development of RP-HPLC method for standardization of Aegle marmelos (L.)
}

\author{
Shelke Smita Panditrao * \\ Gokhale Education Society's Sir Dr. M. S. Gosavi College of Pharmaceutical Education and Research, Prin. T. A. Kulkarni \\ Vidyanagar, Nashik.
}

Publication history: Received on 24 June 2020; revised on 10 July 2020; accepted on 12 July 2020

Article DOI: https://doi.org/10.30574/wjarr.2020.7.1.0226

\begin{abstract}
In recent times, focus on plant research has increased all over the world and several evidences have been collected to show immense potential of medicinal plants used in various traditional systems. Over the last few years, researches have aimed at identifying and validating plant derived substances for the treatment of various diseases. The bael (Aegle marmelos) (L.) is an Indian plant, which has enormous traditional uses against various diseases [1]. The present work aims to compile marmelosin based standardization of Aegle marmelos, generated through the research activity using RP-HPLC as a tool. The method developed was found to be accurate, precise and simple for the stated purpose and can be used routinely for standardization of crude fruit extract and herbal formulations containing it.
\end{abstract}

Keywords: Aegle marmelos; Marmelosin; Standardization; RP-HPLC

\section{Introduction}

Aegle marmelos, also known as bale tree, is a moderate sized, slender, aromatic tree, growing wild throughout the deciduous forests of India. This is generally considered assacred tree by the Hindus, as its leaves are offered to Lord Shiva during worship. Bale fruits are yellowish green, with small dots on the outer surface, oblong to globs, $5.3 \mathrm{~cm}$ to $7.2 \mathrm{~cm}$ in diameter; weight, $77.2 \mathrm{~g}$; pulp, yellow and mucilaginous, the pulp of dried fruits retains its yellow colour, and also remains intact; rind woody, 4 to $5 \mathrm{~mm}$ thick[1].

Various chemical constituents were found in bael such as alkaloids, coumarins, steroids, polysaccharides, tannins, carotenoids etc. Alkaloids: Agelin, aegelenine, marmeline, dictamine, fragrine, 0-methylhalfordinine, 0isopentanylhalford iniol, N-4-methoxy styryl cinnamide. Coumarins: Marmelosin, marmesin, imperatorin, marmin, alloimperatorin, methylether, xanthotoxol, scoparone, scopoletin, umbelliferone, psoralen and marmelide. Polysaccharides: Galactose, arabinose, uronic acid and L-rhamnose was obtained on hydrolysis. Tannin: Tannin was also present in leaves and fruit as skimmianine. Carotenoids were also reported, which impart pale color to fruit[2,3].

Aegle marmelos proved various activities such as anti-diabetic activity, hepatoprotective activity, antimicrobial activity, analgesic, anti-inflammatory, ntipyretic activity, antifungal activity and anticancer activity [3].

The present work is focused to develop method for standardization of Aegle marmelos (bael) fruit pulp used in many herbal preparations, on the basis of marmelosin - a major chemical constituent present $[4,5]$.

\section{Material and methods}

Plant Material: Fruits of Aegle marmelos were collected from local market. The fruit pulp was dried under shade at room temperature for 30 days and kept in incubator at $35^{\circ} \mathrm{C}$ for 15 days. Dried fruit pulp was powdered, sieved and stored in

\footnotetext{
${ }^{*}$ Corresponding author: Shelke Smita Panditrao
}

Copyright (C) 2020 Author(s) retain the copyright of this article. This article is published under the terms of the Creative Commons Attribution Liscense 4.0. 
air tight container until use [4]. Chemicals: Reference standard of marmelosin was obtained from UICT, Mumbai (Maharashtra, India). All the chemicals used in this study were AR Grade.

\subsection{HPLC Method Development \& Optimization}

Physicochemical parameters of marmelosin were studied that includes solubility, partition coefficient, absorption maxima and $\mathrm{pKa}$. The optimized method is as follows;

\subsubsection{Chromatographic Conditions}

Instrument:

Column:

Detection:

Mobile Phase:

Flow Rate:

Injection volume:

Run Time:
Agilent-1220 LC Infinity

Agilent TC-C18, 4.6×5 $\mu \mathrm{m}$

UV-VIS Detector at $247 \mathrm{~nm}$

Acetonitrile: Water (70:30)

$1 \mathrm{ml} / \mathrm{min}$

$20 \mu \mathrm{l}$

20 mins

\subsubsection{Validation of Method: Preparation of standard Solutions}

$10 \mathrm{mg}$ of marmelosin in $10 \mathrm{ml}$ methanol $(1 \mathrm{mg} / \mathrm{ml}$ ). From the stock solution different standard solutions $(1,5,10$, $15,20,25,30 \mu \mathrm{g} / \mathrm{ml}$ ) were prepared in methanol. The developed method was validated for limit of detection, limit of quantitation, linearity, range, accuracy and precision according to ICH guidelines.

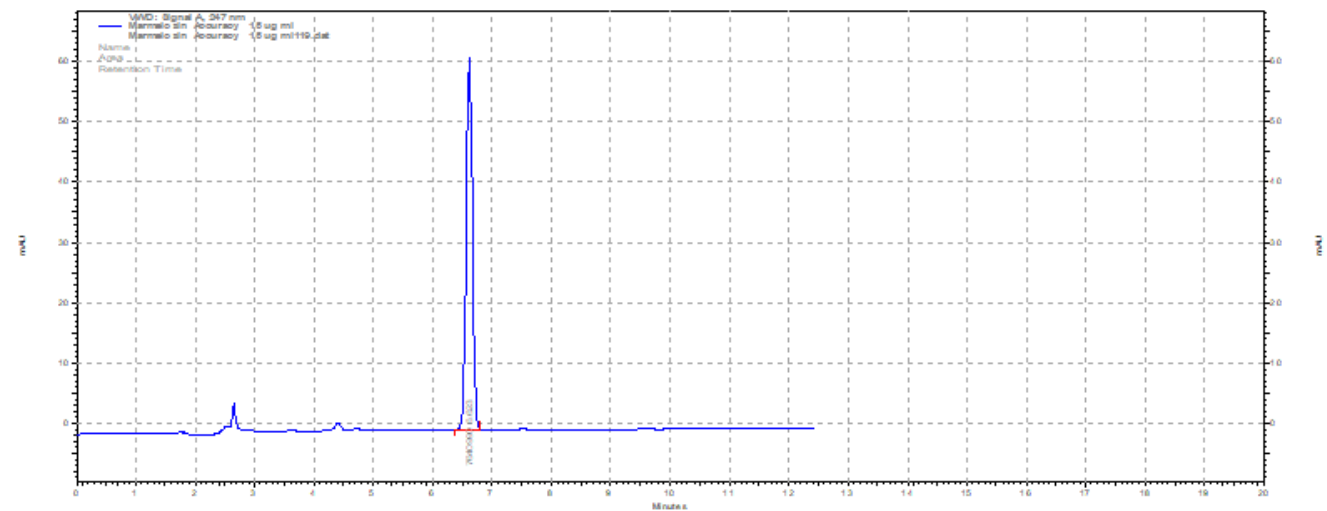

Figure 1 Representative chromatogram of standard marmelosin

\subsubsection{Standardization of crude extract}

The processed fruit pulp was extracted using soxhlet extraction method. The ethanolic extract was used for estimation of marmelosin content in fruit extract. $1 \mathrm{mg}$ of fruit extract was weighed and dissolved in ethanol. Resulting solution was sonicated for $30 \mathrm{mins}$ and filtered through whatman filter paper [4, 6]. Finally $10 \mu \mathrm{g} / \mathrm{ml}$ of sample solutions were prepared and injected on HPLC (Figure No.02). 


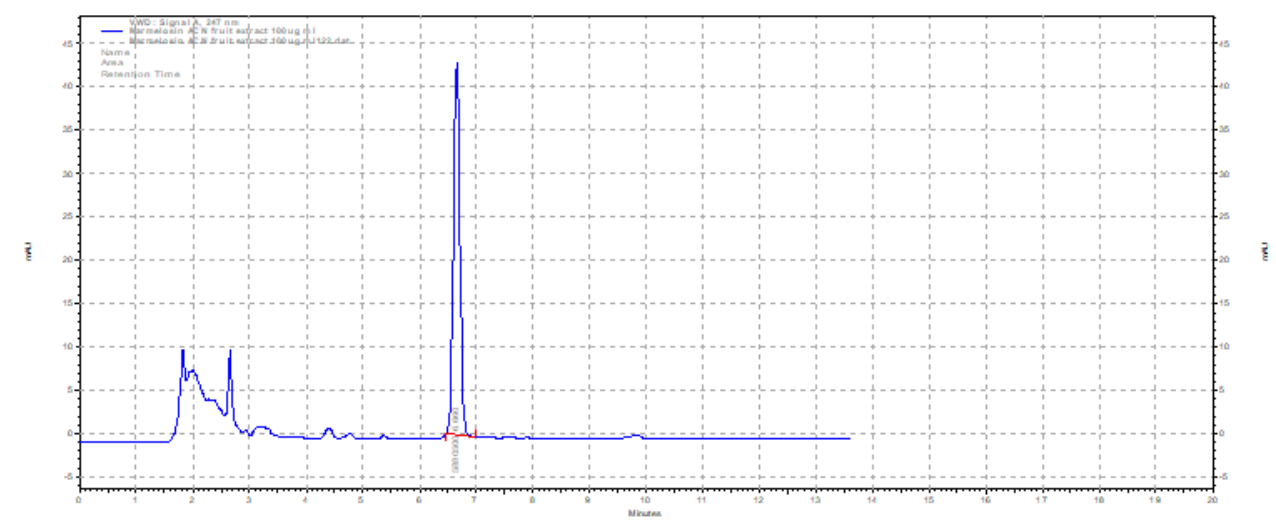

Figure 2 Representative chromatogram of marmelosin from crude extract.

\subsubsection{Assay of herbal preparation}

20 herbal tablets were taken and weighed; quantity equivalent to $10 \mathrm{mg}$ of marmelosin was dissolved in methanol. This solution was sonicated for 30 minutes and filtered using whatmann filter paper. Resulting solution was diluted and injected on HPLC (Figure No.03).

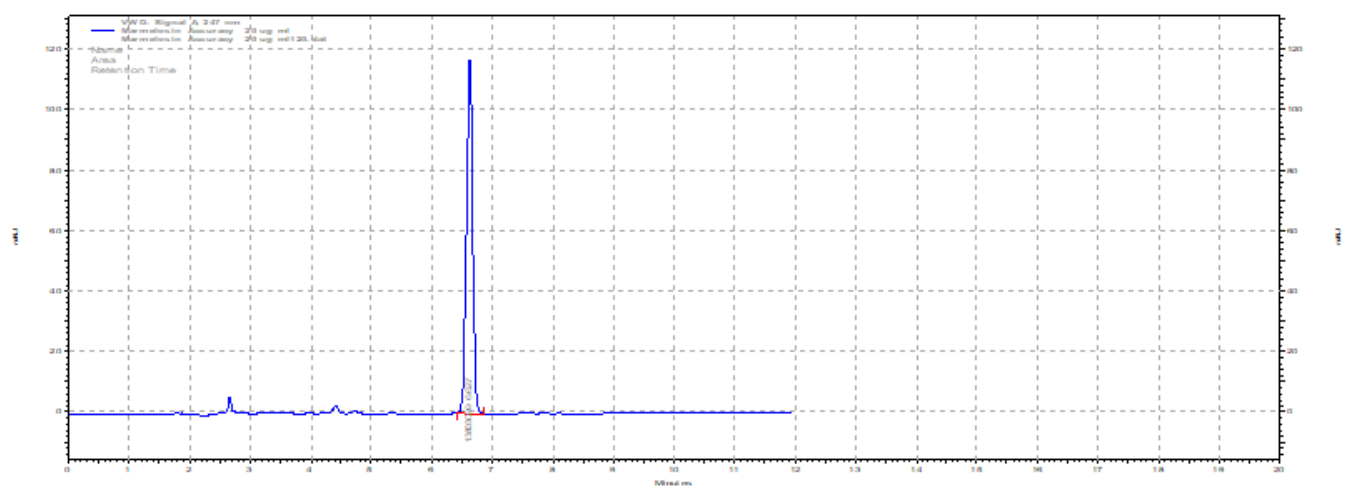

Figure 3 Representative chromatogram of marmelosin of herbal preparation.

\section{Results and Discussion}

Aegle marmelos (bael) fruit have many pharmacological activities since it is used from the traditional days hence need to be studied. Marmelosin is one of the major chemical constituent of the bael fruit and used as a biomarker. HPLC method was selected for the purpose because chromatographic methods are more accurate and sensitive.

The reported methods $[4,6]$ has very low sensitivity and required long time for marmelosin to elute. Therefore method was modified and optimized. Acetonitrile: Water (70:30) was used as mobile phase, flow rate was $1 \mathrm{ml} / \mathrm{min}$ and $\lambda_{\max }$ was $247 \mathrm{~nm}$. Method has validated for LOD, LOQ, linearity, precision and accuracy. LOD and LOQ were found to be $0.1 \mathrm{mg}$ / $\mathrm{ml}$ and $1 \mathrm{mg} / \mathrm{ml}$ respectively. Method was linear in the range $1-30 \mu \mathrm{g} / \mathrm{ml}$ with $\mathrm{r}^{2}=0.998$. A precision study shows that coefficient of variance less than 20. This indicates that method was precise. Accuracy study was performed by percentage recovery method. The percent recovery was found to be $95 \%$. The marmelosin content of crude ethanolic extract of fruit pulp of Aegle marmelos was found to be $8.1 \% \mathrm{w} / \mathrm{w}$. The percent purity of herbal formulation of Aegle marmelos for marmelosin content was found to be $95 \%$.

\section{Conclusion}

The developed and validated method was sensitive, accurate, precise and economic. It can be used for standardization of any formulation of Aegle marmelos. 


\section{Compliance with ethical standards}

\section{Acknowledgments}

The Author is thankful to the principal and management of Gokhale Education Society's Sir Dr. M. S. Gosavi College of Pharmaceutical Education and Research Nashik-05 for providing support and facilities for the present work.

\section{Disclosure of conflict of interest}

The author declares that there is no conflict of interest. If there are potential conflicts of interest, we highly encourage each author to identify and declare clearly to avoid any future investigations by the publisher.

\section{References}

[1] Charoensiddhi S and Anprung P. (2008). Bioactive compounds and volatile compounds of Thai bael fruit Aegle marmelos (L.) Correa as a valuable source for functional food ingredients. International Food Research Journal, 15(3), 287-295.

[2] Pallab M, Dananjay H, Uday B and Dipak KM. (2009). Biological activities of crude extract and chemical constituents of Bael, Aeglemarmelos (L.) Corr. Indian Journal of Experimental Biology, 47, 849-861.

[3] Ganesh NS. (2011). Medicinal Values of Bael (Aeglemarmelos) (L.) Corr. International journal of current pharmaceutical reviews and research, 1(3), 12 - 22.

[4] Sunita S. (2012). Marmelosin Based Standardization of Ayurvedic Formulations Containing Aegle marmelos Using RP-HPLC Method', Journal of Pharmacy Research, 5(4), 2224-2227.

[5] Yogita B and Gulshan B. (2011). Analytical methods for standardization of Aegle marmelos. A review. J Pharm Educ Res, 2(2), 37-43.

[6] Mosihuzzaman M, Iqbal M and Choudhary. (2008). Protocols on Safety, efficacy, standardization, and documentation of herbal medicine. Pure Appl. Chem, 80(10), 2195-2230.

\section{How to cite this article}

Shelke SP. (2020). Development of RP-HPLC method for standardization of Aegle marmelos (L.). World Journal of Advanced Research and Reviews, 7(1), 129-132. 